\title{
Nauplius
}

The Journal of The

Brazilian Crustacean Society

This article is part of the tribute offered

by the Brazilian Crustacean Society

in memoriam of Michael Türkay

outstanding contribution to Carcinology

e-ISSN 2358-2936

www.scielo.br/nau

www.crustacea.org.br

Original Article

\section{Observation of museum specimens of the genus Pacifastacus Bott, 1950 (Decapoda: Astacidae)}

\author{
Tadashi Kawai ${ }^{1}$ iD orcid.org/0000-0001-5988-0493
}

1 Wakkanai Fisheries Institute. 4-5-15 Suehiro, Wakkanai, Hokkaido 097-0001, Japan.

ZOOBANK http://zoobank.org/urn:lsid:zoobank.org:pub:611FD951-02D5-43DA9501-7CEE88B8CFB7

\section{Abstract}

Until recently, three subspecies had traditionally been recognized in the astacid species Pacifastacus leniusculus (Dana, 1852): Pacifastacus leniusculus leniusculus, Pacifastacus leniusculus klamathensis (Stimpson, 1857), and Pacifastacus leniusculus trowbridgii (Stimpson, 1857). The type specimens attributed to these taxa were re-described with detailed illustrations of taxonomic characteristics for further taxonomic works.

\section{KEY WORDS}

Crayfish, klamathensis, leniusculus, Neartic region, taxonomy, trowbridgii.

\section{INTRODUCTION}

The signal crayfish, Pacifastacus leniusculus (Dana, 1852), is an indigenous

CORRESPONDING AUTHOR Tadashi Kawai kawai-tadashi@hro.or.jp

SUBMITTED 15 May 2017 ACCEPTED 6 December 2017 PUBLISHED 8 January 2018

Guest Editor

Célio Magalhães

DOI 10.1590/2358-2936e2018001

\section{(cc) BY}

All content of the journal, except where identified, is licensed under a Creative Commons attribution-type BY

Nauplius, 26: e2018001 
figures are limited to the illustrations of the whole body of P. l. leniusculus (cf. Dana, 1852; Stimpson, 1857). This is considered to be inadequate for a future taxonomic work and a more detailed description of the respective types or museum specimens, as well as illustrations of body parts, are deemed necessary.

This paper provides a detailed description along with illustrations of the taxa, based on their type specimens. As carapace morphology (including rostrum) is considered to be very important to discriminate the three taxa (Miller, 1960; Hobbs, 1972), illustrations of their carapace and other taxonomically important characteristics are presented.

Measurements of crayfish structures followed Hobbs (1972) and were made to the nearest $0.1 \mathrm{~mm}$ with a precision dial caliper and an eye-piece micrometer installed on a stereomicroscope. Abbreviations used in the text are: POCL, postorbital carapace length; TCL, total carapace length; USNM, National Museum of Natural History, Smithsonian Institution, Washington, D.C.; SMF, Forschungsinstitut und Naturmuseum Senckenberg, Frankfurt.

\section{Pacifastacus leniusculus leniusculus (Dana, 1852) \\ (Figs. 1, 2; Tab. 1)}

Description of the syntypes. Eye large (diameter 3.4 $\mathrm{mm}$ ). Cephalothorax (Fig. 1A) subcylindrical, thoracic section dorsoventrally depressed, feebly tuberculated dorsally and dorsolaterally, cephalic section laterally with moderately large tubercles, areola 2.0 times as long as wide, constituting $28.5 \%$ of TCL (38.9\% of POCL). Rostrum (Fig. 1B, C) non-serrate, margins converging from base to base of acumen, broad at base and lacking median carina, with moderately elevated, slightly thickened margins bearing tubercles, weakly converging to base of acumen, with single right (left 1 ) marginal tubercles; length of acumen greater than width of rostrum at level of marginal spines, margins not constricted at base of acumen, more strongly converging and moderately concave to dorsally directed apex, tip reaching cephalic to distal margin of antennal scale and not reaching distal margin of penultimate podomere of antennular peduncle, acumen comprising $46.8 \%$ of rostrum length, latter comprising $30.5 \%$ of TCL; floor (dorsal surface) of rostrum minutely punctate, suborbital ridge not visible in dorsal aspect, postorbital ridge moderately developed, poorly defined dorsally, with dorsolateral groove, spiniform cephalically and pair of spines at posterior bases.

Carapace as wide as the greatest width of abdomen.

Abdominal pleuron subangular (Fig. 1D) with margins slightly rounded, surface punctate, terga slightly punctate, articular surfaces glabrous. Proximal podomere of uropod (Fig. 2K) with small caudolateral spine on lobe, larger spine on mesial lobe; mesial ramus of uropod with moderate caudolateral spine, and strong median ridge terminating in moderate, submarginal caudomedian spine, lateral ramus of uropod with caudolateral spine; telson with two spines at each caudolateral corner of cephalic section, having transverse suture.

Incisor region of mandible blade-like (Fig. 2B). Antennal scale (Fig. 2C) 2.3 times as long as broad, widest at midlength. Third maxilliped (Fig. 2D) with tip of endopodite extending nearly to distal margin of penultimate podomere of antennal scale peduncle; mesial margin of merus (Fig. 2E) with row of spines, and that of distal end largest; tip of basal podomere of exopodite extending beyond midlength of merus of endopodite, longitudinal ridge of ventrolateral margin of ischium with punctate row, ventrolateral half of ischium punctate, distolateral corner with small tubercle, ventromesial half with long, obscuring bristles on mesial margin, latter with denticles, distomesial corner having large spine.

Epistome (Fig. 2A) with wide, nearly semicircular cephalic lobe, lateral margins of lobe moderately thickened, slightly elevated ventrally, floor (ventral surface) of lobe plane, covered finely punctate, lacking setae; subtruncate lateral corners, lamellae small, punctate; central depression of body broad, fovea weak, lacking spine or ridge posterior to renal papilla; zygoma slightly arched, cephalolateral margins flanked by usual pits.

Total length of cheliped $80.3 \%$ of TCL, mesial margin of palm (Fig. 1E) 0.7 times wider than long, 1.3 times wider than deep, articular ridge strong, dorsal and ventral surfaces punctate, lacking tubercles, distolateral part with weak depression and moderate pits, not costate, articular ridge strong. Fingers of chela not gaping; opposable surface of fixed finger with row of 13 moderate tubercles; lateral surface 

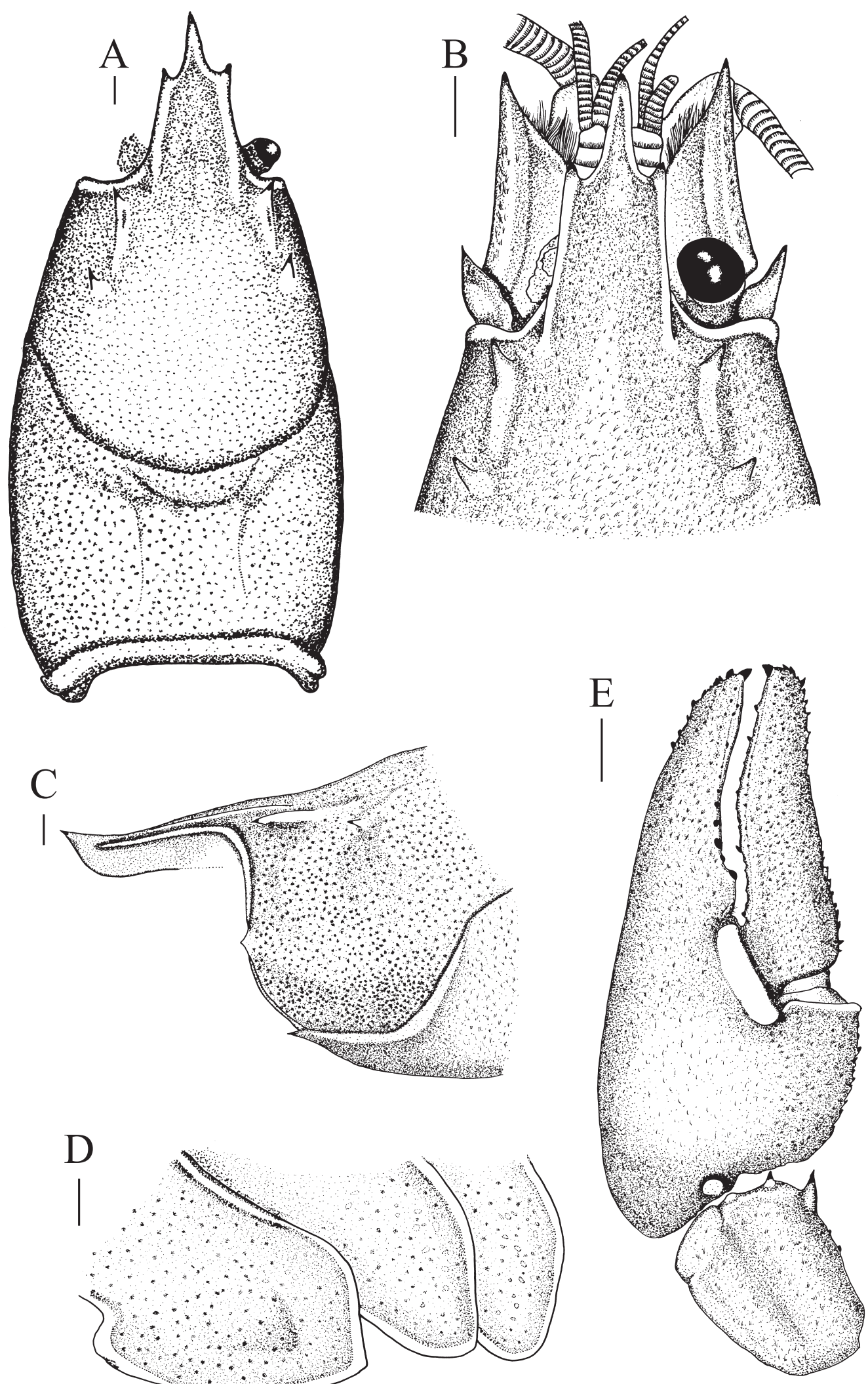

Figure 1. Pacifastacus leniusculus leniusculus (Dana, 1852): all figures from syntypic male (USNM 44408). A, Dorsal view of carapace; B, dorsal view of rostrum; C, cephalolateral view of carapace; D, lateral view of second to fourth pleonal somites; E, dorsal view of left cheliped. Scale bars $=2 \mathrm{~mm}$. 
A

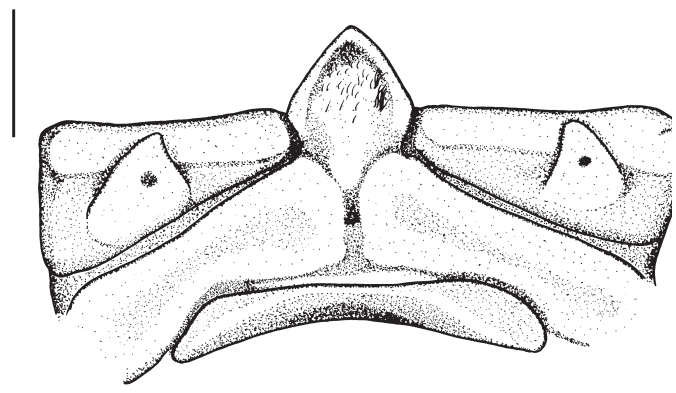

B

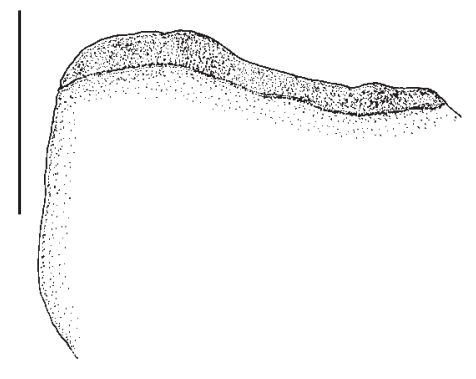

C

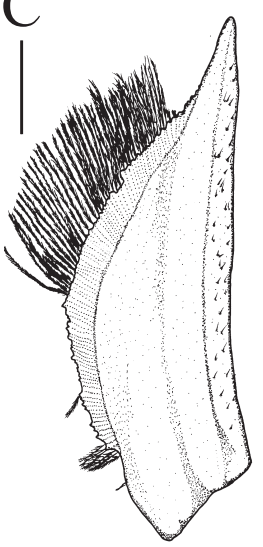

D

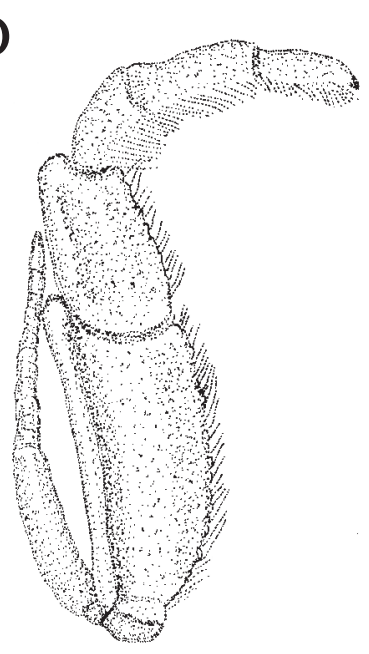

$\mathrm{E}$

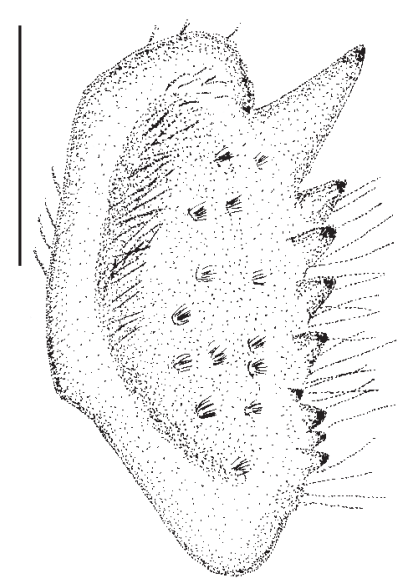

F

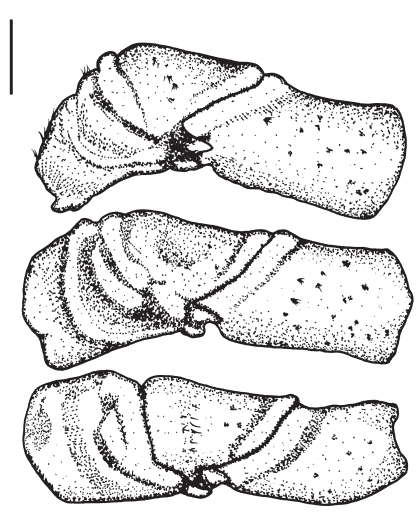

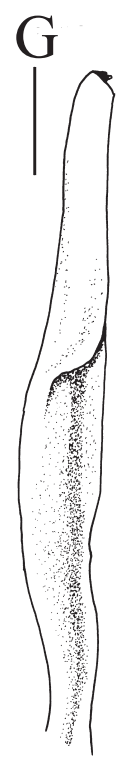
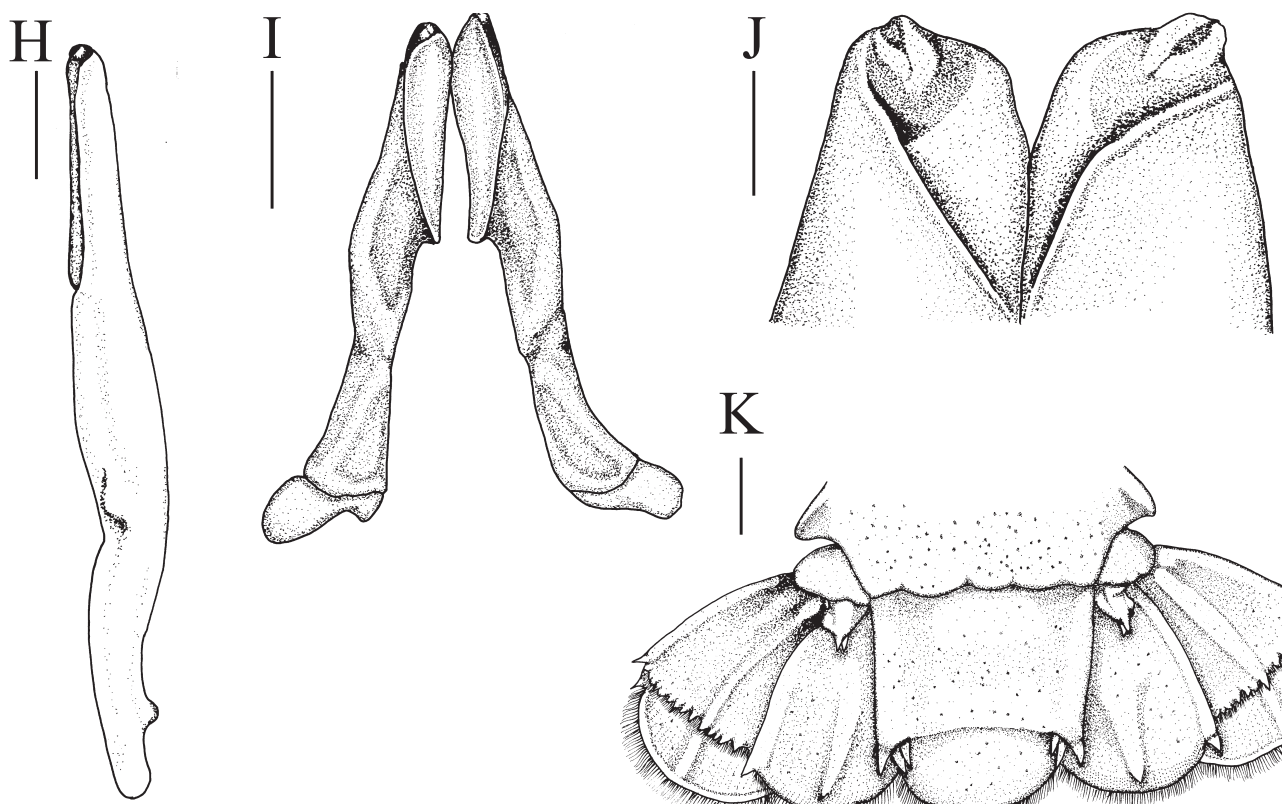

$\mathrm{K}$

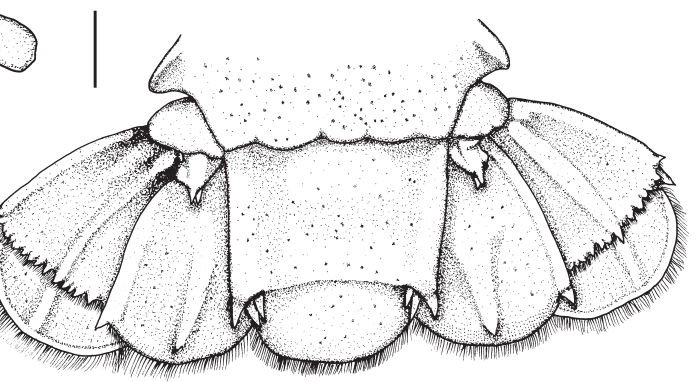

Figure 2. Pacifastacus leniusculus leniusculus (Dana, 1852): all figures from syntypic male (USNM 44408). A, Epistome and base of antennae; B, distocaudal view of denticle of mandible; C, dorsal view of antennal scale; D, ventral view of third maxilliped; E, dorsal view of merus of third maxilliped; F, proximal podomeres of pereiopods; G, mesial view of first pleopod; H, lateral view of first pleopod (gonopod); I, ventral view of first pleopod; J, ventral view of distal portion of first pleopod; K, dorsal view of telson and uropods. Scale bars $=2 \mathrm{~mm}$, except $\mathrm{B}=0.5 \mathrm{~mm}$. 
moderate, not having costation and row of tubercles, dorsal surface and ventral surface with tuft of setae originating from pits, lacking longitudinal ridge. Fixed finger dorsolaterally with very weakly costate, dorsal and ventral surfaces with tuft of setae originating from pits, lacking longitudinal ridge, opposable surface with row of 19 conical and equal size tubercles. Dactyl of chelae 1.9 times as long as mesial margin of palm, comprising $56.6 \%$ of total chela length, dorsal surface of dactyl lacking longitudinal ridge, mesial surface with seta originating from pits, ventral surface punctate, lacking ridge; opposable surface with single row of equal size tubercles. Carpus of cheliped 1.3 times as long as wide, 1.1 times length of mesial margin of palm, dorsal surface with long, slightly oblique sulcus, surface lateral and mesial sides along sulcus with pits, mesial surface of carpus with large, strong tubercles, ventral surface with conical distal mounds, distomesial one tipped with spine. Merus of cheliped 2.2 times longer than greatest depth, length $35.1 \%$ of TCL.

Lacking hook on ischia of pereiopods (Fig. 2F). Gonopods (first pleopods) (Fig. 2G-I) of male symmetrical in caudal aspect, well developed, distal portion (Fig. 2J) rolled and contracted to form narrow tube, lacking lobes apically. Length of tubular part 3 times longer than gonopod length; distal portion converging to tip, lacking distal portion corneous.

Deposition and type locality. The syntypic series is comprised of three males: male \#1 (USNM 2161),

Table 1. Measurements (mm) of the syntypes of Pacifastacus leniusculus leniusculus (Dana, 1852) deposited at the National Museum of Natural History (USNM) and male specimen of P. leniusculus klamathensis (Stimpson, 1857) deposited at the Forschungsinstitut und Naturmuseum Senckenberg (SMF).

\begin{tabular}{|c|c|c|c|c|}
\hline Structures & $\begin{array}{c}\text { Male\#1 } \\
\text { syntype USNM } 2161\end{array}$ & $\begin{array}{l}\text { Male\#2 syntype } \\
\text { USNM } 2019\end{array}$ & $\begin{array}{c}\text { Male \#3 syntype } \\
\text { USNM } 44408\end{array}$ & $\begin{array}{c}\text { Male\#3 } \\
\text { SMF } 1437\end{array}$ \\
\hline \multicolumn{5}{|l|}{ Carapace } \\
\hline Total length & 30.0 & - & 45.6 & 42.0 \\
\hline Postorbital length & 21.2 & 34.6 & 33.4 & \\
\hline Length cephalic & 29.1 & - & 32.6 & \\
\hline Width & & 21.4 & 21.3 & 21.8 \\
\hline Depth & 10.8 & 14.2 & 16.1 & 16.9 \\
\hline Length rostrum & 8.9 & - & 13.9 & \\
\hline Length acumen & 4.2 & - & 6.5 & \\
\hline Length areola & 8.2 & 12.8 & 13.0 & \\
\hline Width areola & 4.2 & 6.9 & 6.5 & \\
\hline \multicolumn{5}{|l|}{ Antennal scale } \\
\hline Length & 6.9 & 10.3 & 9.6 & \\
\hline Width & 2.7 & 4.4 & 4.1 & \\
\hline \multicolumn{5}{|l|}{ Abdomen } \\
\hline Length & 28.1 & 41.6 & 41.7 & \\
\hline Width & 13.0 & 20.9 & 20.4 & 13.4 \\
\hline \multicolumn{5}{|l|}{ Cheliped } \\
\hline $\begin{array}{l}\text { Length lateral } \\
\text { margin chela }\end{array}$ & 21.7 & 33.3 & 36.6 & 38.0 \\
\hline $\begin{array}{l}\text { Length mesial } \\
\text { margin palm }\end{array}$ & 6.8 & 9.4 & 11.1 & 12.5 \\
\hline Width palm & 8.6 & 12.3 & 15.2 & \\
\hline Depth palm & 4.8 & 6.4 & 8.3 & 9.8 \\
\hline Length dactyl & 11.7 & 20.1 & 20.7 & 21.8 \\
\hline Length carpus & 6.8 & 10.9 & 12.0 & \\
\hline Width carpus & 5.8 & 8.2 & 9.6 & \\
\hline $\begin{array}{l}\text { Length dorsal } \\
\text { margin merus }\end{array}$ & 9.0 & 16.2 & 16.0 & 17.8 \\
\hline $\begin{array}{l}\text { Greatest depth } \\
\text { merus }\end{array}$ & 5.0 & 7.9 & 7.4 & \\
\hline Gonopod length & 8.3 & 11.2 & 12.5 & 10.8 \\
\hline
\end{tabular}


male \#2 (USNM 2019) and male \#3 (USNM 44408) from Columbia River and Puget Sound, Washington (Dana, 1852; Hobbs, 1974).

\section{Pacifastacus leniusculus klamathensis (Stimpson, 1857) \\ (Figs. 3, 4; Tab. 1)}

Description of male. (Male\#3, SMF 1437). Cephalothorax (Fig. 4A) subcylindrical; thoracic section dorsoventrally depressed, feebly tuberculated dorsally and dorsolaterally, cephalic section laterally with moderate tubercles. Rostrum (Fig. 4B) nonserrate, margins converging from base to base of acumen, broad at base and lacking median carina, with moderately elevated, slightly thickened margins and tubercles, latter weakly converging to base of acumen, with single right side (left 1 ) weak marginal tubercles, more strongly converging and moderately concave to dorsally directed apex, tip of which reaching cephalic to distal margin of antennal scale and not reaching distal margin of penultimate podomere of antennular peduncle, length of acumen seldom equal to width of rostrum at level of marginal tubercles, floor (dorsal surface) of rostrum with small spots, suborbital ridge not visible in dorsal aspect, postorbital ridge rounded, poorly defined dorsally, with dorsolateral groove and not having tubercles at posterior bases.

Carapace 1.3 times wider than greatest width of abdomen, abdominal pleura with margins subangular (Fig. 4D), terminal slightly rounded, surface punctate, terga slightly punctate, articular surfaces glabrous. Proximal podomere of uropod with small caudolateral spine on lobe, larger spine on mesial lobe, mesial ramus of uropod with moderate caudolateral spine, and strong median ridge terminating in moderate, submarginal caudomedian spine, lateral ramus of uropod with caudolateral spine.

Epistome (Fig. 4E) with wide, nearly semicircular cephalic lobe bearing very small cephalomedian projection, lateral margins of lobe moderately thickened, slightly elevated ventrally, floor (ventral surface) of lobe plane, covered with very small marks, lacking setae; lamellae small, punctate, subtruncate lateral corners, lacking spine or ridge posterior to renal papilla; central depression of body broad, fovea weak, zygoma slightly arched, cephalolateral margins flanked by usual pits.
Third maxilliped with tip of endopodite nearly extending to distal margin of penultimate podomere of antennal scale peduncle; tip of basal podomere of exopodite extending beyond midlength of merus of endopodite; mesial margin of merus (Fig. 4F) with two spines, spine of distal end larger; longitudinal ridge of ventrolateral margin of ischium with row of marks, ventrolateral half of ischium punctuate, distolateral corner with small tubercle, ventromesial half with long, obscuring bristles on mesial margin, latter with denticles, distomesial corner having larger spine.

Total length of cheliped $90.5 \%$ of TCL, mesial margin of palm (Fig. 4C) 1.3 times wider than deep, articular ridge strong, dorsal and ventral surfaces punctate, lacking tubercles, distolateral part with weak depression and moderate punctuations marks, not costate, articular ridge strong. Fingers of chela not gaping, lateral surface not costate and row of tubercles, dorsal surface and ventral surface with tuft of seta originating from marks, lacking longitudinal ridge, opposable surface of fixed finger with row of moderate tubercles. Fixed finger dorsolaterally very weakly costate, dorsal and ventral surfaces with tuft of seta originating from marks, lacking longitudinal ridge, opposable surface with row of conical and equal size tubercles. Dactyl of chelae 1.7 times as long as mesial margin of palm, comprising $57.4 \%$ of total chela length, dorsal surface of dactyl lacking longitudinal ridge, mesial surface with seta originating from marks, ventral surface punctate, lacking ridge, opposable surface with single row of equal size tubercles. Dorsal surface of carpus with long, slightly oblique sulcus, surface lateral and mesial to sulcus punctate; mesial surface of carpus with large, strong tubercles; ventral surface with conical distal mounds, distomesial one tipped with spine. Merus of cheliped length $42.4 \%$ of TCL.

Gonopods (first pleopods) (Fig. 4G) of male symmetrical in caudal aspect. Second pleopod (Fig.4H, I) single stout shaft with deep suture near midlength, exopodite originating from suture not reaching distal margin of endopodite, palps originating on distal portion of shaft.

Examined specimen and type locality. In the original description, Stimpson (1857) noted that the type locality is Lake Klamath and collected by Dr. Newberry. The type series, however, is not extant, and Faxon 


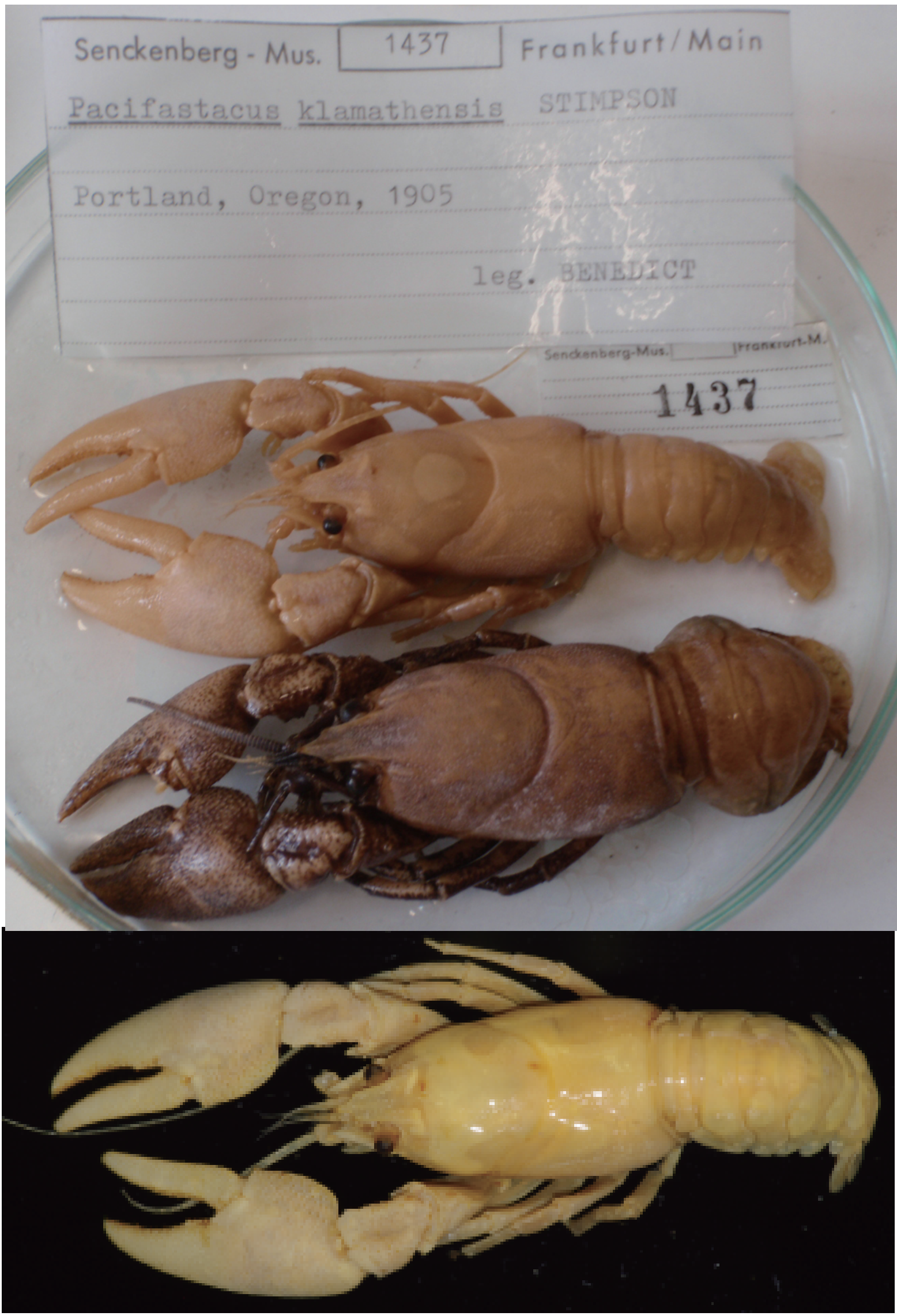

Figure 3. Pacifastacus leniusculus klamathensis (Stimpson, 1857). Lot SMF 1437: current label, male \#3, and female (upper); male \#3 (lower). 

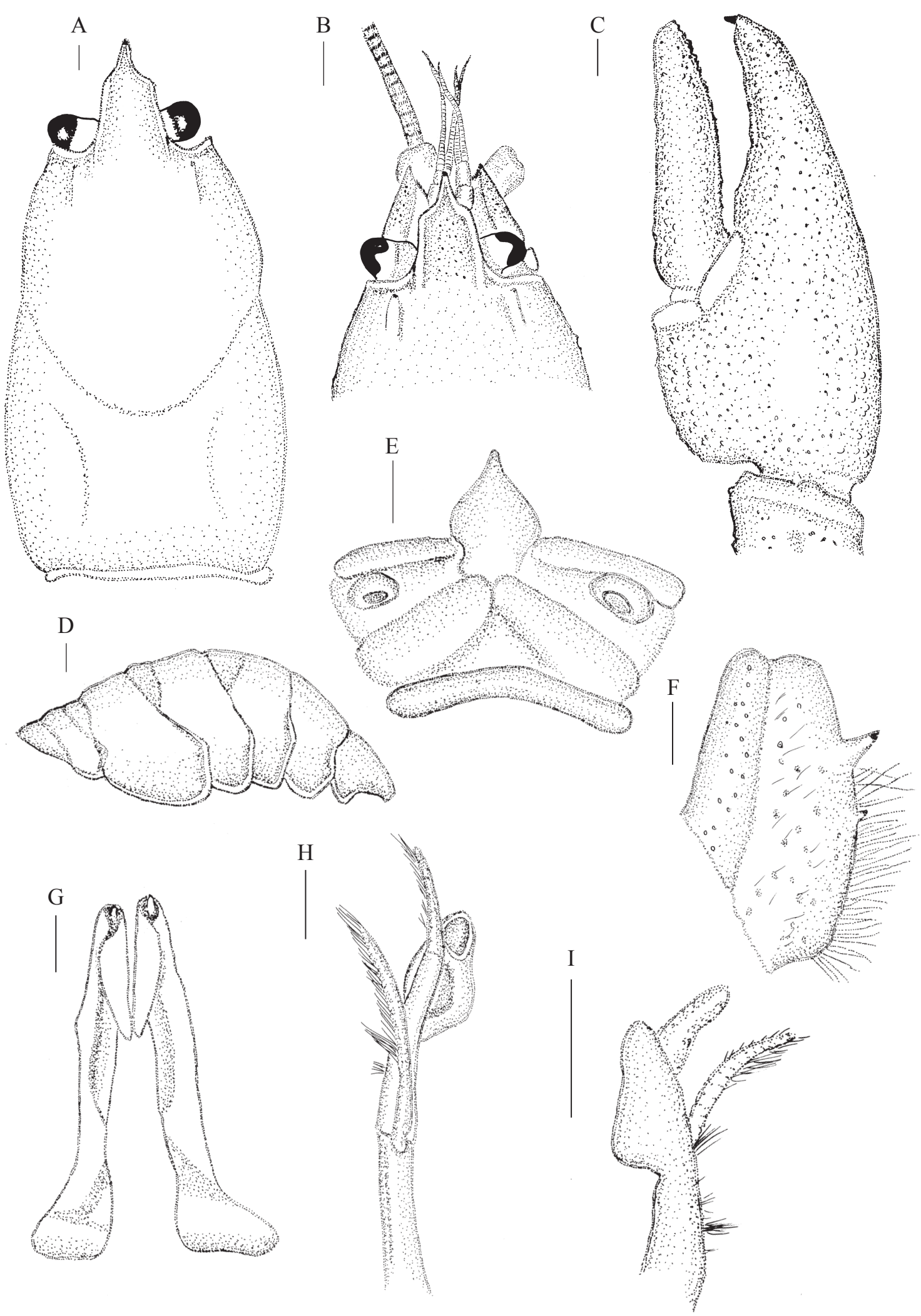

Figure 4. Pacifastacus leniusculus klamathensis (Stimpson, 1857) (SMF 1437). A, Dorsal view of carapace; B, dorsal view of rostrum; C, dorsal view of cheliped; D, lateral view of second to fourth pleonal somites; E, epistome and base of antennae; F, dorsal view of merus of third maxilliped; G, ventral view of gonopod (first pleopod); H, mesial view of second pleopod; I, lateral view of second pleopod. Scale bars $=2 \mathrm{~mm}$. 
(1914: 409) mentioned that "probably destroyed in the Chicago fire in 1871".

Pacifastacus leniusculus klamathensis was originally described as Astacus leniusculus, then Bott (1950) revised their genus name into Pacifastacus based on the specimen SMF 1437, which was collected from Portland, Oregon (Fig. 3). The specimen is the namebearing type of the genus Pacifastacus.

\section{Pacifastacus leniusculus trowbridgii (Stimpson, 1857) \\ (Figs. 5, 6; Tab. 2)}

Description of the syntypes. Eye large (diameter $3.4 \mathrm{~mm}$ ), cephalothorax (Fig. 5A) subcylindrical, thoracic section dorsoventrally depressed, feebly tuberculated dorsally and dorsolaterally, cephalic section laterally with moderate tubercles, areola 2.5 times as long as wide, constituting $33.9 \%$ of TCL (42.4\% of POCL). Rostrum (Fig. 5B) non-serrate, margins converging from base to base of acumen, broad at base and lacking median carina, with moderately elevated, slightly thickened margins and tubercles, latter weakly converging to base of acumen, with single right side (left 1) marginal tubercles, length of acumen seldom equal to width of rostrum at level of marginal spines, margins not constricted at base of acumen, more strongly converging and moderately concave to dorsally directed apex, tip of which reaching slightly cephalic to distal margin of antennal scale and not reaching distal margin of penultimate podomere of antennular peduncle, acumen comprising $43.9 \%$ of rostrum length, latter comprising $21.4 \%$ of TCL, floor (dorsal surface) of rostrum with small marks, suborbital ridge not visible in dorsal aspect, postorbital ridge rounded or tuberculiform cephalically and with or without low tuberculiform prominences at posterior bases (Fig. 5B, C).

Carapace (Fig. 5A, B) 1.1 times wider than greatest width of abdomen, abdominal pleura with margins subangular (Fig. 5E), terminal slightly rounded, surface punctate, terga slightly punctuate, articular surfaces glabrous. Incisor region of mandible dentate-crenate (Fig. 6A). Proximal podomere of uropod (Fig. 5F) with small caudolateral spine on lobe, larger spine on mesial lobe, mesial ramus of uropod with moderate caudolateral spine, left lateral ramus of uropod with caudolateral spine; telson with two (1 in left) spines at caudolateral corner of cephalic section, lacking transverse suture.

Antennal scale (Fig. 6B) 2.1 times as long as broad, widest at midlength, lateral margin thickened and terminating in long distal spine. Third maxilliped with tip of endopodite extending nearly to distal margin of penultimate podomere of antennal scale peduncle, tip of basal podomere of exopodite extending beyond midlength of merus of endopodite; mesial of merus (Fig. 6C) with row of spines, spine of distal end largest; longitudinal ridge of ventrolateral margin of ischium with row of punctuations; ventrolateral half of ischium punctate, distolateral corner with small tubercle, ventromesial half with long, obscuring bristles on mesial margin, latter with denticles, distomesial corner having larger spine.

Total length of cheliped $107.6 \%$ of TCL, mesial margin of palm (Fig. 5D) 0.9 times wider than long, 1.5 times wider than deep; articular ridge strong, proximal margin well defined, ventral surface punctuated, lacking tubercles, distolateral part with weak depression and moderately punctate, not costate, articular ridge strong. Fingers of chela not gaping, dorsal surface and ventral surface with punctuation, not costate, lacking longitudinal ridge, opposable surface of fixed finger with row of 13 (9 left) moderate tubercles. Fixed finger not costate, dorsal and ventral surfaces punctate, lacking longitudinal ridge, opposable surface with row of conical and equal size tubercles. Dactyl of chelae 1.4 times as long as mesial margin of palm, comprising $54.1 \%$ of total chela length; dorsal surface of dactyl lacking longitudinal ridge, mesial surface with seta originating from marks, ventral surface punctate, lacking ridge, opposable surface with single row of equal size tubercles. Carpus of cheliped 1.1 times as long as wide, 0.8 times length of mesial margin of palm, dorsal surface with long, slightly oblique sulcus, surface lateral and mesial to sulcus punctate, mesial surface of carpus with large, strong spines, ventral surface with conical distal mounds, distomesial one tipped with spine. Merus of cheliped 1.8 times longer than greatest depth, length $39.4 \%$ of TCL; dorsal surface with single row of large, small tubercles; ventrolateral ridge with large, stout tubercles, ventromesial ridge with stout, acute tubercles.

Ischia of pereiopods lacking hook (Fig. 6D). Gonopods (first pleopods) (Fig. 6E) of male 


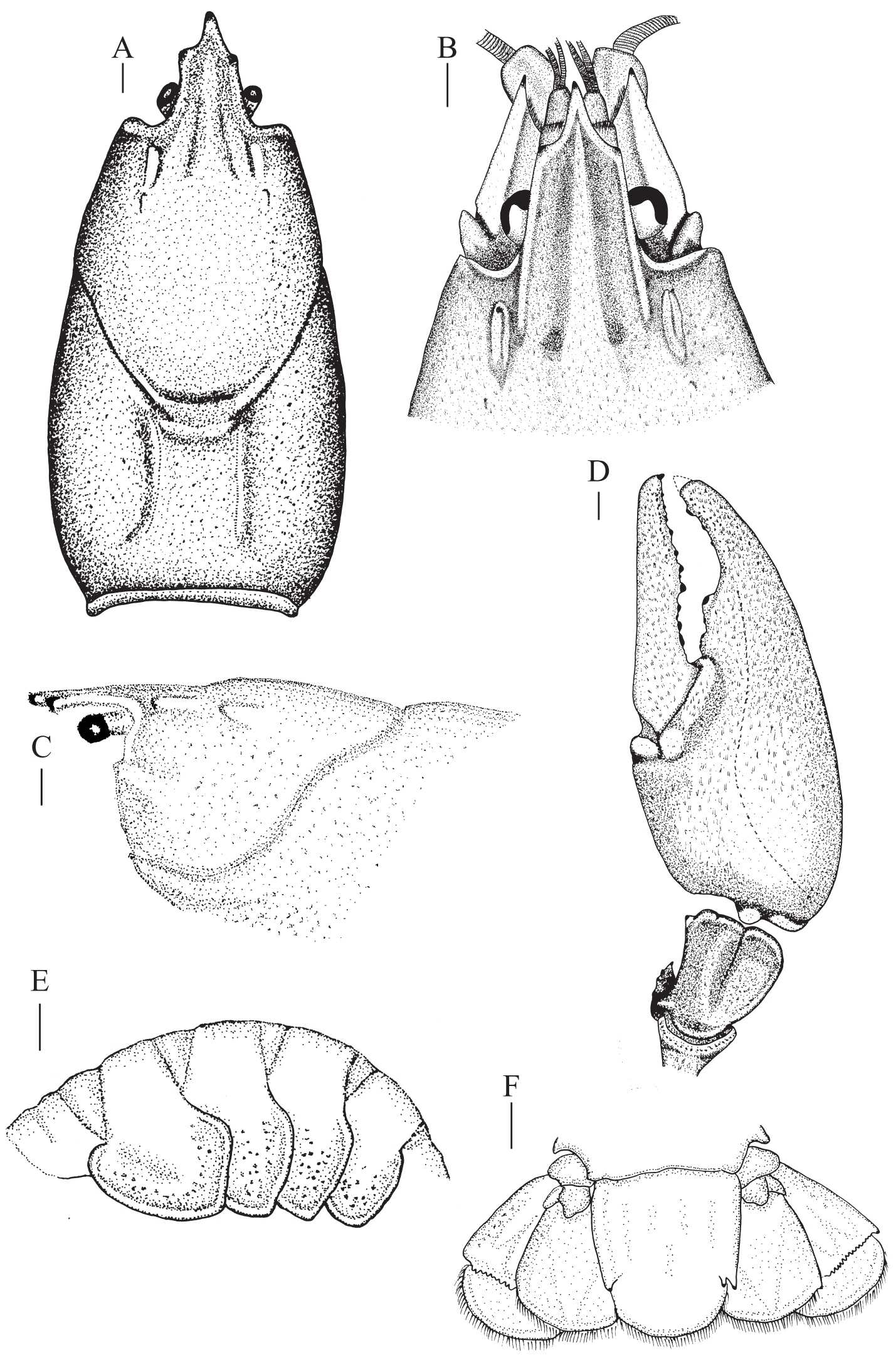

Figure 5. Pacifastacus leniusculus trowbridgii (Stimpson, 1857): all figures from syntypic male \#1 (USNM 2080). A, Dorsal view of carapace; B, dorsal view of rostrum; C, cephalolateral view of carapace; D, dorsal view of cheliped; E, lateral view of second to fifth pleonal somites; F, dorsal view of telson and uropods. Scale bars $=2 \mathrm{~mm}$. 
A
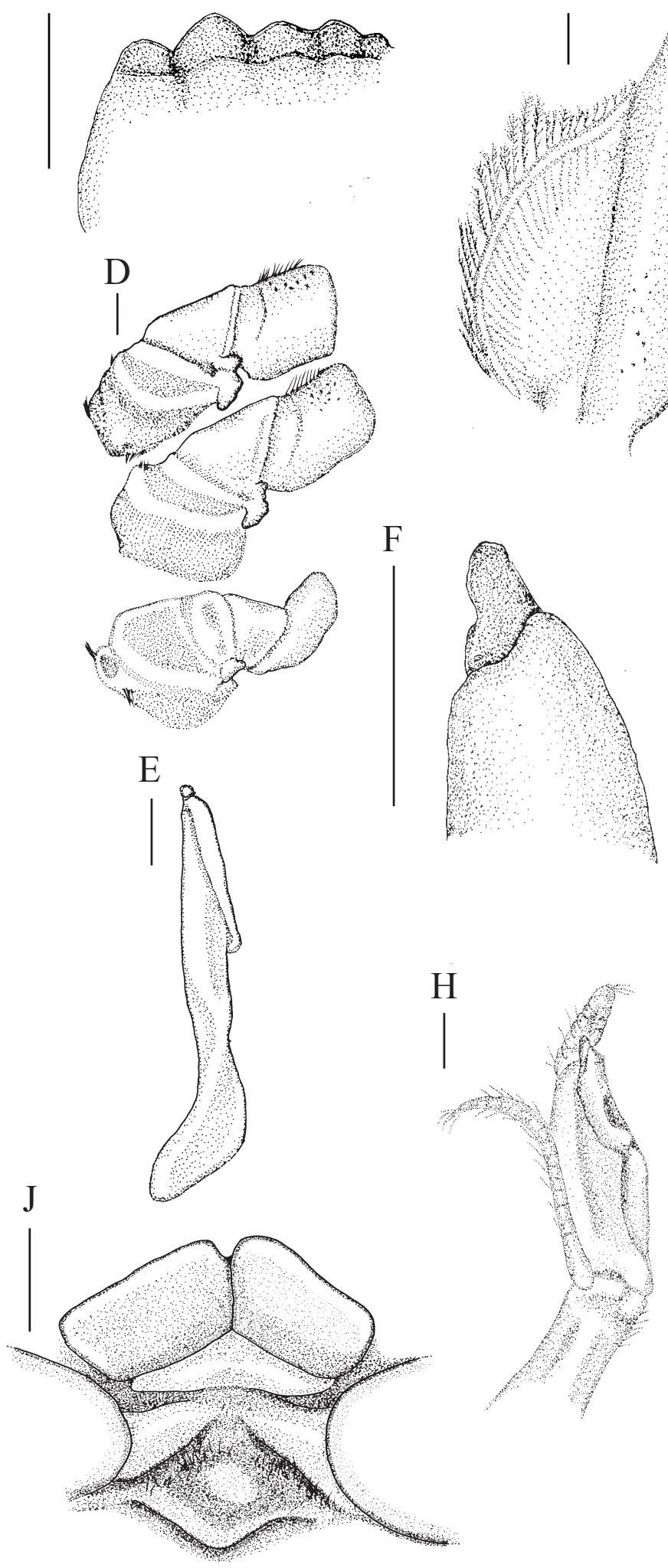

$\mathrm{C}$
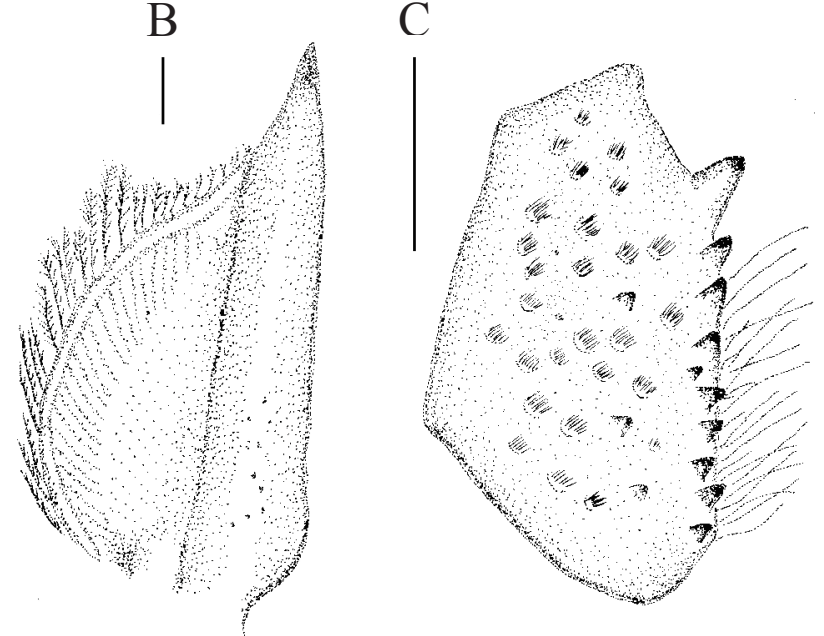

G
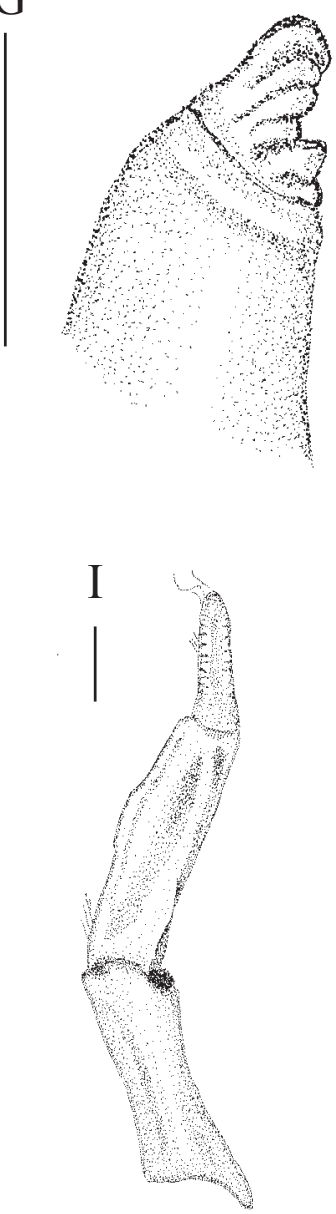

Figure 6. Pacifastacus leniusculus trowbridgii (Stimpson, 1857): all figures from syntypic male \#1 (USNM 2080) except J, from syntypic female \#1 (USNM 2080). A, Distocaudal view of denticle of mandible; B, dorsal view of antennal scale; C, dorsal view of merus of third maxilliped; D, proximal podomeres of pereiopods; E, mesial view of first pleopod; F, mesial view of distal portion of first pleopod; G. lateral view of distal portion of first pleopod; H, mesial view of second pleopod; I, lateral view of second pleopod; $\mathrm{J}$, caudal thoracic sternal area of female. Scale bars $=2 \mathrm{~mm}$, except $\mathrm{A}=0.5 \mathrm{~mm}$. 
Table 2. Measurements (mm) of the syntypes (USNM 2080) of Pacifastacus leniusculus trowbridgii (Stimpson, 1857).

\begin{tabular}{|c|c|c|c|}
\hline Structures & Male \# 1 & Female \# 1 & Male \#2 \\
\hline \multicolumn{4}{|l|}{ Carapace } \\
\hline Total length & 61.7 & 42.5 & 44.8 \\
\hline Postorbital length & 49.3 & 33.0 & 33.9 \\
\hline Length cephalic section & 40.8 & 29.1 & 31.0 \\
\hline Width & 32.0 & 21.8 & 21.3 \\
\hline Depth & 23.7 & 15.3 & 15.9 \\
\hline Length rostrum & 13.2 & 9.2 & 11.5 \\
\hline Length acumen & 5.8 & 4.9 & 5.0 \\
\hline Length areola & 20.9 & 13.4 & 13.8 \\
\hline Width areola & 8.3 & 5.2 & 7.2 \\
\hline \multicolumn{4}{|l|}{ Antennal scale } \\
\hline Length & 10.3 & 7.9 & 9.8 \\
\hline Width & 5.0 & 3.9 & 3.6 \\
\hline \multicolumn{4}{|l|}{ Abdomen } \\
\hline Length & 53.9 & 42.2 & 39.8 \\
\hline Width & 28.8 & 24.3 & 19.7 \\
\hline \multicolumn{4}{|l|}{ Cheliped } \\
\hline $\begin{array}{l}\text { Length lateral } \\
\text { margin chela }\end{array}$ & 66.4 & 35.8 & 42.3 \\
\hline $\begin{array}{l}\text { Length mesial } \\
\text { margin palm }\end{array}$ & 26.4 & 12.0 & 15.0 \\
\hline Width palm & 29.2 & 16.5 & 17.9 \\
\hline Depth palm & 17.4 & 9.5 & 10.5 \\
\hline Length dactyl & 35.9 & 18.9 & 23.1 \\
\hline Length carpus & 20.0 & 12.0 & 13.7 \\
\hline Width carpus & 18.4 & 11.3 & 11.7 \\
\hline $\begin{array}{l}\text { Length dorsal } \\
\text { margin merus }\end{array}$ & 24.3 & 14.8 & 17.7 \\
\hline $\begin{array}{l}\text { Greatest depth } \\
\text { merus }\end{array}$ & 13.7 & 8.8 & 9.0 \\
\hline Gonopod length & 15.7 & 12.3 & $\mathrm{~N} / \mathrm{A}$ \\
\hline
\end{tabular}

symmetrical in caudal aspect, well developed, distal portion (Fig. 6F, G) rolled and contracted to form narrow tube, lacking lobes apically. Length of tubular part 3 times longer than gonopod length; distal portion converging to tip, lacking corneous distal portion. Second pleopod (Fig. 6H, I) single stout shaft with deep suture near midlength, exopodite originating from suture not reaching distal margin of endopodite, palps originating on distal portion of shaft. Annulus ventralis of female lacking (Fig. 6J).

Deposition and type locality. The syntypes of $P$. leniusculus trowbridgii are 2 males and 2 females (USNM 2080) collected by Lt. Trowbridge from Columbia River, above Astoria (Stimpson, 1857).

\section{ACKNOWLEDGeMENTS}

The author thank Dr. Y. Hanamura for valuable comments on an early version of the manuscript, Dr. R. Lemaitre (USNM) for providing access to the collections, and Prof. M. Türkay (Forshungsinstitut und Naturmuseum Senckenberg), who kindly invited me to Frankfurt to discuss mutual topics on interest on the genus Pacifastacus.

\section{References}

Agerberg, A. 1990. Genetic variation in three species of freshwater crayfish; Astacus astacus L., Astacus leptodactylus Aesch., and Pacifastacus leniusculus (Dana), revealed by isozyme electrophoresis. Hereditas, 113: 101-108. 
Agerberg, A. 1993. Genetic and phenotypic variation in the freshwater crayfish P. leniusculus (Dana). Acta Universitatis Upsaliensis, Comprehensive summaries of Uppsala dissertations from the Faculty of Science 446, 28p.

Agerberg, A. and Jansson, H. 1995. Allozymic comparisons between three subspecies of the freshwater crayfish Pacifastacus leniusculus (Dana), and between populations introduced to Sweden. Hereditas, 122: 33-39.

Bott, R. 1950. Die Flusskrebse Europas (Decapoda, Astacidae). Abhandlungen der Senckenbergischen naturforschenden Gesellschaft, 483: 1-36, figs. 1-23, pls. 1-6.

Dana, J.D. 1852 United States Exploring Expedition During the Years 1838 to 1842 Under the Command of Charles Wikes U.S.N. Crustacea, Vol. 13. Philadelphia, C. Sherman, 1620p.

Faxon, W. 1914. Notes on the crayfishes in the United States National Museum and the Museum of Comparative Zoology with descriptions of new species and subspecies to which is applied a catalogue of the known species and subspecies. Memories of the Museum of Comparative Zoology at Harvard College, 40: 351-428, 13 pls.

Hobbs, H.H., Jr. 1972. Crayfishes (Astacidae) of North and Middle America. Water Pollution Control Research Series, Identification Manual 9. Washington, DC, United States Environmental Protection Agency.

Hobbs, H.H., Jr. 1974. A checklist of the North and Middle American crayfishes (Decapoda: Astacidae and Cambaride).
Smithsonian Contributions to Zoology, 166: 1-161.

Larson, E.R. and Williams, B.W. 2015. Historical biogeography of Pacifastacus crayfishes and their branchiobdellidan and entocytherid ectosymbionts in Western North America. p. 404-447. In: T. Kawai; G. Scholtz and Z. Faulkes (eds), Freshwater Crayfish: Global Overview. Florida, CRC Press.

Larson, R.R.; Abbott, C.L.; Usio, N.; Azuma, N.; Wood, A.; Herborg, L-M. and Olden, J.D. 2012. The signal crayfish is not a single species: cryptic diversity and invasions in the Pacific Northwest range of Pacifastacus leniusculus. Freshwater Biology, 57: 1823-1838.

Miller, G.C. 1960. The taxonomic and certain biological aspects of the crayfish of Oregon and Washington. Oregon States College, Corvallis, USA, Master Thesis. 216p. Available at http://ir.library.oregonstate.edu/xmlui/handle/1957/11587. Accessed on 10 February 2016.

Riegel, J.A. 1959. The systematic and distribution of crayfishes in California. California Fish and Game, 45: 29-50.

Sonntag, M.M. 2006. Taxonomic standing of the three subspecies of Pacifastacus leniusculus, and their phylogeographic patterns in the Klamath basin area. Bringham Young University, Provo, UT, Master Thesis.

Stimpson, W. 1857. Notice of new species of Crustacea in Western North America; being an abstract from a paper to be published in the Journal of the Society. Proceedings of Boston Society of Natural History, 6: 84-89. 